\title{
Ranking of hydropower projects based on sustainability criteria in India using multicriteria decision making methods
}

\author{
Anuja Shaktawat ${ }^{1}$, Shelly Vadhera ${ }^{2}$ \\ ${ }^{1}$ School of Renewable Energy and Efficiency, National Institute of Kurukshetra, Kurukshetra, Haryana, India \\ ${ }^{2}$ Department of Electrical Engineering, National Institute of Kurukshetra, Kurukshetra, Haryana, India
}

\section{Article Info \\ Article history: \\ Received Feb 12, 2021 \\ Revised Mar 6, 2021 \\ Accepted Jun 16, 2021}

\section{Keywords:}

Hydropower projects

Multi-criteria decision making

Sustainability assessment

Sustainability criteria

Sustainable development

\begin{abstract}
Assessment of hydropower projects with respect to sustainability criteria is a multidimensional and a complex issue that decision makers usually face during planning process. In hydropower projects, it is important to consider technical, environmental and social parameters instead of purely economic ones for sustainability assessment and decision making. Multi-criteria decision making (MCDM) methods offer a practical approach to a problem having conflicting criteria. The flexibility to consider several criteria and objectives simultaneously made MCDM methods well accepted in the field of energy planning. This paper aims for applicability of MCDM methods which will facilitate the decision makers to select the most sustainable hydropower projects by making real and logical choices based on various sustainability criteria. For comprehensively rank hydropower projects of Indian region based on sustainability criteria four MCDM methods are applied i.e., analytic hierarchy process (AHP), technique for order of preference by similarity to ideal solution (TOPSIS), preference ranking organization method for enrichment evaluations (PROMETHEE II) and elimination and choice translating reality (ELECTRE III). To ensure better decision making the eight criteria selected are compatible to the sustainable development of hydropower projects.
\end{abstract}

This is an open access article under the CC BY-SA license.

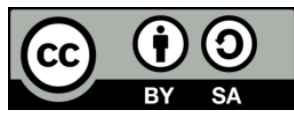

Corresponding Author:

Anuja Shaktawat

School of Renewable Energy and Efficiency

National Institute of Technology Kurukshetra

NIT, Mirzapur Part, Haryana 136118, India

Email: shaktawateanu090@gmail.com

\section{INTRODUCTION}

Hydropower is recognized as a mature technology for electricity generation and is globally contributing maximum towards the generation of all the renewable resources. Hydropower has storage reservoir, which helps to meets the peak load demand and thus stabilize the overall electrical grid [1]. Hydropower apart from generating low-cost electricity provides water supply, flood control, drought management, recreation, irrigation, and job creation [2], [3]. Regardless of these several advantages, the development of hydropower used to be highly controversial on account of it's social and environmental impacts in terms of loss of biodiversity, destroying of the ecosystem, greenhouse gas (GHG) emissions, submergence of large land area, displacement and resettlement of population [4]. Therefore, in the field of hydropower development sustainability has become an important concern.

Previously technical and economic parameters were the main criteria to analyze the hydropower projects which mainly focused on electricity generation [5]. Later environmental and social aspects were also considered as significant criteria for sustainability assessment of hydropower projects [6]. Hence it becomes 
necessary to consider all i.e., technical, economic, social and environmental criteria for assessing the sustainability of hydropower project. However, these criteria are contradicting as it is not possible to design an economical, high installed capacity hydropower project with negligible environmental and social impacts, further some impacts are bound to happen. Therefore, to tackle the hydropower system with a perception of sustainability as a complex problem, multi-criteria decision making (MCDM) methods serve as a quite realistic approach which includes, among others, some conflicting criteria [7].

There are several MCDM methods which are widely applied to the application of energy planning, sustainability assessment and ranking of renewable energy projects such as hydropower, wind, solar, geothermal, etc. For example, analytic hierarchy process (AHP) is applied in [8] to study the potential to develop hydropower projects. To assisting energy planning [9] also used AHP to evaluate and rank the hydropower projects specifically to the hydropower plants constructions in the mountainous area of Italy and [10] used AHP to determine the most suitable site for a wind observation station. Preference ranking organization method for enrichment evaluations (PROMETHEE) method with fuzzy input data has been used to assessed and ranked alternative energy exploitation schemes of a low-temperature geothermal field using [11]. Moreover [12] developed the framework using the PROMETHEE method to arrive for group consent on renewable energy projects, which was then applied to a geothermal reservoir project on the island of Chios and [13] applied PROMETHEE for assessing the sustainability of renewable energy technologies in Scotland. Elimination and choice translating reality (ELECTRE) method had been applied by [14] and [15] in the application of renewable energy planning. Technique for order of preference by similarity to ideal solution (TOPSIS) under fuzzy environment has been used for evaluating sustainability and ranking of renewable energy technologies [16]-[18]. The MCDM methods help in better decision making by efficiently considering numerous criteria with conflicting nature. Depending on the objective of planning and application area, each MCDM method has its own strength and weakness [19]. Hence no single method can be categorized as best or worst.

The present study demonstrates the application of most often used MCDM methods namely AHP, TOPSIS, PROMETHEE II, and ELECTRE III on a practical example for ranking of major hydropower projects of India based on eight sustainability criteria. The AHP method is used to evaluate the weights of the criteria used for assessing the sustainability of hydropower projects. The various criteria considered for ranking of hydropower projects in this study are based on techno-economic, economic, environmental and social.

\section{METHODOLOGY}

\subsection{Weights calculation by AHP method}

The AHP introduced by Saaty is the most widely accepted decision support tool for complicated decision problems [20]. AHP uses a multi-level hierarchical formation of objectives, criteria, sub-criteria, and alternatives.

The following steps are involved in the AHP method [21].

(i) Construct a pairwise comparisons matrix of the criteria involved in the decision using a numerical scale for comparison used in [20]. Let $\mathrm{C}_{j}(j=1,2, \ldots, \mathrm{n})$ represents the $j^{\text {th }}$ criteria. B presents the $(n \times n)$ pairwise comparison matrix, where $\mathrm{b}_{i j}(i, j=1,2, \ldots, \mathrm{n})$ represents the relative importance of criteria $i$ with respect to criteria $j$. A criterion compared with itself is always assigned the value 1 .

$$
B=\left[\begin{array}{cccc}
1 & b_{12} & \ldots & b_{1 n} \\
b_{21} & 1 & \ldots & b_{2 n} \\
\ldots & \ldots & \ldots & \ldots \\
b_{n 1} & b_{n 2} & \ldots & 1
\end{array}\right] b_{j i}=1 / b_{i j}, b_{i j} \neq 0
$$

(ii) The relative normalized weight (Wi) is calculated by calculating the value of the geometric mean $\left(G M_{i}\right)$ of its row.

$$
\begin{aligned}
& G M_{i}=\left\{b_{i 1} \times b_{i 2} \times b_{i 3} \times \ldots \times b_{i j}\right\}^{1 / n} \\
& W_{i}=\frac{G M_{i}}{\sum_{j=1}^{j=n} G M_{i}}
\end{aligned}
$$

(iii) Determine the matrix $\mathrm{Y}$ such that $\mathrm{Y}=B \times W$, where

$$
W=\left[W_{1}, W_{2}, W_{3}, \ldots, W n\right]^{T}
$$




$$
Y=B * W=\left[\begin{array}{cccc}
1 & b_{12} & \ldots & b_{1 n} \\
b_{21} & 1 & \ldots & b_{2 n} \\
\ldots & \ldots & \ldots & \ldots \\
b_{n 1} & b_{n 2} & \ldots & 1
\end{array}\right]\left[\begin{array}{c}
W_{1} \\
W_{2} \\
\ldots \\
W_{n}
\end{array}\right]=\left[\begin{array}{c}
C_{1} \\
C_{2} \\
\ldots \\
C_{n}
\end{array}\right]
$$

(iv) The consistency values (CV) calculated for the group of alternatives is given by (6).

$$
C V_{i}=\frac{C_{i}}{W_{i}}
$$

(v) The value of the maximum eigenvalue $\lambda \max$ is then calculated which is the average of the consistency values.

(vi) The value of the consistency index $(C I)=(\lambda \max -n) /(n-1)$ is calculated wherein ' $n$ ' denotes the total number of criteria. The consistency of the pairwise comparison denotes the quality of the results of the AHP.

(vii) The value of the random index (RI) is selected using Table 1 for the number of criteria.

(viii) The value of consistency ratio $(\mathrm{CR})=\mathrm{CI} / \mathrm{RI}$ is then calculated. The value 0.1 is the accepted upper limit for $\mathrm{CR}$. If the value of $\mathrm{CR}$ exceeds the value 0.1 , then complete evaluation procedure has to be repeated to improve consistency as the value of CR denotes the consistency of decision makers as well as of overall hierarchy.

Table 1. Random index $(R I)$ values [21]

\begin{tabular}{cccc}
\hline Criteria & RI & Criteria & RI \\
\hline 3 & 0.52 & 7 & 1.35 \\
4 & 0.89 & 8 & 1.4 \\
5 & 1.11 & 9 & 1.45 \\
6 & 1.25 & 10 & 1.49 \\
\hline
\end{tabular}

\subsection{Methods for ranking of alternatives}

\subsubsection{The TOPSIS method}

The TOPSIS method, developed by Hwang and Yoon [22], is based on the principle that the best alternative is closest to the positive ideal solution and farthest from the negative ideal solution [23], [24]. The formal TOPSIS method comprises of the following steps:

(i) A decision matrix has to be established for the ranking wherein columns represent criteria $\left(C_{1}, C_{2}, C_{3}\right.$, $\left.\ldots, C_{n}\right),(\mathrm{j}=1,2, \ldots, \mathrm{n})$ while rows represent alternatives $\left(A_{1}, A_{2}, A_{3}, \ldots A_{m}\right),(\mathrm{i}=1,2, \ldots, \mathrm{m})$.

$$
\begin{aligned}
& \begin{array}{llll}
C_{1} & C_{2} & \ldots & C_{n}
\end{array} \\
& \begin{array}{llll}
\left(W_{l}\right) & \left(W_{2}\right) & \ldots & \left(W_{n}\right)
\end{array} \\
& A_{1}\left[\begin{array}{cccc}
X_{11} & X_{12} & \ldots & X_{1 n}
\end{array}\right. \\
& A_{2} \quad \begin{array}{lllll}
X_{21} & X_{22} & \ldots & X_{2 n}
\end{array} \\
& A_{m} \longleftarrow X_{m 1} \quad X m 2 \quad X m n
\end{aligned}
$$

An element $X_{i j}$ of the matrix indicates the performance rating of the $i^{\text {th }}$ alternative $\mathrm{A}_{i}$, with respect to the $j^{\text {th }}$ criteria $\mathrm{C}_{j}$, as shown in (7).

(ii) The normalized decision matrix rij of $\mathrm{Xij}$ is calculated as defined in (8)

$$
r_{i j}=\frac{X_{i j}}{\sqrt{\sum_{i=1}^{i=m} X_{i j}^{2}}} i=1,2, \ldots, m ; j=1,2, \ldots, n
$$

(iii) Weighted normalized decision matrix $v_{i j}$ is calculated by multiplying the normalized decision matrix by its corresponding weights.

$$
v_{i j}=W_{j} * r_{i j}
$$

(iv) The values of positive ideal (best) $(\mathrm{V}+)$ and negative ideal (worst) solutions ( $\mathrm{V}-$ ) is then calculated using (10) and (11). 


$$
\begin{aligned}
& \mathrm{V}+=\left\{\left(\sum_{i}^{\max } v_{i j} / j \in J\right),\left(\sum_{i}^{\min } v_{i j} / j \in J^{\prime}\right) / i=1,2, \ldots, m\right\} \\
& =\left\{v_{1}^{+}, v_{2}^{+} v_{3, \ldots}^{+}, v_{n}^{+}\right\} \\
& V^{-}=\left\{\left(\sum_{i}^{\min } v_{i j} / j \in J\right),\left(\sum_{i}^{\max } v_{i j} / j \in J^{\prime}\right) / i=1,2, \ldots, m\right\} \\
& =\left\{v_{1}^{-} v_{2}^{-}, v_{3,}^{-} \ldots, v_{n}^{-}\right\}
\end{aligned}
$$

where $J=(j=1,2, \ldots, \mathrm{n}) / j$ is set of beneficial criteria and $J^{\prime}=(j=1,2, \ldots, \mathrm{n}) / j$ is set of nonbeneficial criteria.

(v) The separation between alternatives can be calculated by the n-dimensional Euclidean distance. The separation of each alternative from the positive ideal solution is given as (12).

$$
S_{i}^{+}=\sqrt{\sum_{J=1}^{n} v_{i j}-v_{j}^{+2}} i=1,2, \ldots, m
$$

Similarly, the separation from the negative ideal solution is as (13).

$$
S_{i}^{-}=\sqrt{\sum_{J=1}^{n} v_{i j}-v_{j}^{-2}} i=1,2, \ldots, m
$$

(vi) The relative closeness of the alternative Aij from the ideal solution, is calculated as (14).

$$
R_{i}=\frac{S_{i}^{-}}{S_{i}^{+}+S_{i}^{-}}(14)
$$

(vii) Finally, the alternatives are ranked in the descending order according to the value of $R_{i}$.

\subsubsection{The PROMETHEE method}

The PROMETHEE is an effective MCDM tool and popular outranking method [25]. In PROMETHEE method a finite ' $m$ ' number of alternatives $A=[A 1, A 2, \ldots, A m]$ are evaluated for a finite ' $n$ ' number of evaluation criteria $\mathrm{C}=[\mathrm{C} 1, \mathrm{C} 2, \ldots, \mathrm{Cn}]$. PROMETHEE has proved to be an excellent tool for ranking considering multiple and complex criteria when dealing with the finite number of alternatives [26], [27]. The versions available of PROMETHEE are PROMETHEE I, PROMETHEE II, PROMETHEE III, PROMETHEE IV and PROMETHEE VI. Based on the user-friendly approach and mathematical property, each PROMETHEE method can be regarded as a convenient tool for decision making [28].

In present study PROMETHEE II is applied as it is the most commonly used version which allows decision maker to find a full ranked vector of alternatives and it is well fitted to the case study undertaken. In this method, alternatives are evaluated by pairwise comparison on a particular criterion and based on the deviation the preference is assigned for the best alternative by a decision maker. The preference assigned is the value between ' $0-1$ ' that is according to the selected preference function. The six preference functions had been proposed by [25], which are namely, usual criterion (Type I), quasi criterion (Type II), criterion with linear preference (Type III), level criterion (Type IV), criterion with linear preference and indifference area (Type V), and Gaussian criterion (Type VI) [29]. The introduction of an indifference threshold in decision making will decide the selection of Type I or IV; and Type III or V preference function.

The preference of alternative A1 over alternative $\mathrm{A} 2$ for a particular criterion $C_{j}$ can be determined by means of a preference function $P_{j}\left(A_{1}, A_{2}\right)$ such that $0 \leq P_{j}\left(A_{1}, A_{2}\right) \geq 1$, which expresses the preference as a function of the deviation $d_{j}\left(A_{1}, A_{2}\right)$ between $\mathrm{A} 1$ and $\mathrm{A} 2$ on that particular criterion:

$$
P_{j}\left(A_{1}, A_{2}\right)=F_{j}\left[d_{j}\left(A_{1}, A_{2}\right)\right]=F_{j}\left[C_{j}\left(A_{1}\right)-C_{j}\left(A_{2}\right)\right]
$$

where $F_{j}$ represents the function of the deviation. Figure 1 presents the linear preference function, which requires to define the parameters $q_{j}$ i.e., indifference threshold and $p_{j}$ i.e., outright preference threshold for each criterion considered. The parameter $q_{j}$ is defined as the largest deviation, which is considered negligible by the decision maker. The parameter $p_{j}$ is defined as the smallest deviation, which is considered sufficient to generate a full preference [25]. The index of preference $\Pi\left(A_{1}, A_{2}\right)$ of alternative $A_{1}$ being preferred over alternative $A_{2}$ is given by (16). 


$$
\Pi\left(A_{1}, A_{2}\right)=\frac{\sum_{j=1}^{n} P_{j}\left(A_{1}, A_{2}\right) W_{j}}{\sum_{j=1}^{n} W_{j}}
$$

$\Pi\left(A_{1}, A_{2}\right)$ is a number between 0 and 1 that represents the degree to which $A_{1}$ is preferred over $A_{2}$, while $\Pi\left(A_{2}, A_{1}\right)$ represents the preference of $A_{2}$ over $A_{1} \cdot W_{j}$ is the weight assigned to criteria $j$. To rank one alternative against all the other alternatives, the positive and negative outranking flows given by (17) and (18) are calculated and finally, net outranking flow is calculated by (23).

$$
\begin{aligned}
& \emptyset^{+}\left(A_{1}\right)=\frac{1}{(n-1)} \sum_{B \in A} \prod\left(A_{1}, B\right) \\
& \emptyset^{-}\left(A_{1}\right)=\frac{1}{(n-1)} \sum_{B \in A} \prod\left(B, A_{1}\right) \\
& \emptyset\left(A_{1}\right)=\emptyset^{+}\left(A_{1}\right)-\emptyset^{-}\left(A_{1}\right)
\end{aligned}
$$

The positive outranking flow $\emptyset^{+}\left(A_{1}\right)$ in (17) indicates how the alternative $A_{1}$ is outranking all the others, while the negative outranking flow $\emptyset^{-}\left(A_{1}\right)$ in (18) indicates how the alternative $A_{1}$ is outranked by all the others. Higher the $\emptyset^{+}\left(A_{1}\right)$ and lower the $\emptyset^{-}\left(A_{1}\right)$ indicates, $A_{1}$ is better in comparison to the other alternatives. The value of the net outranking flow $(\varnothing)$ calculated for each alternative using (19) is used to rank the alternatives. The highest rank will be assigned to the alternative with the greatest value of $\emptyset$.

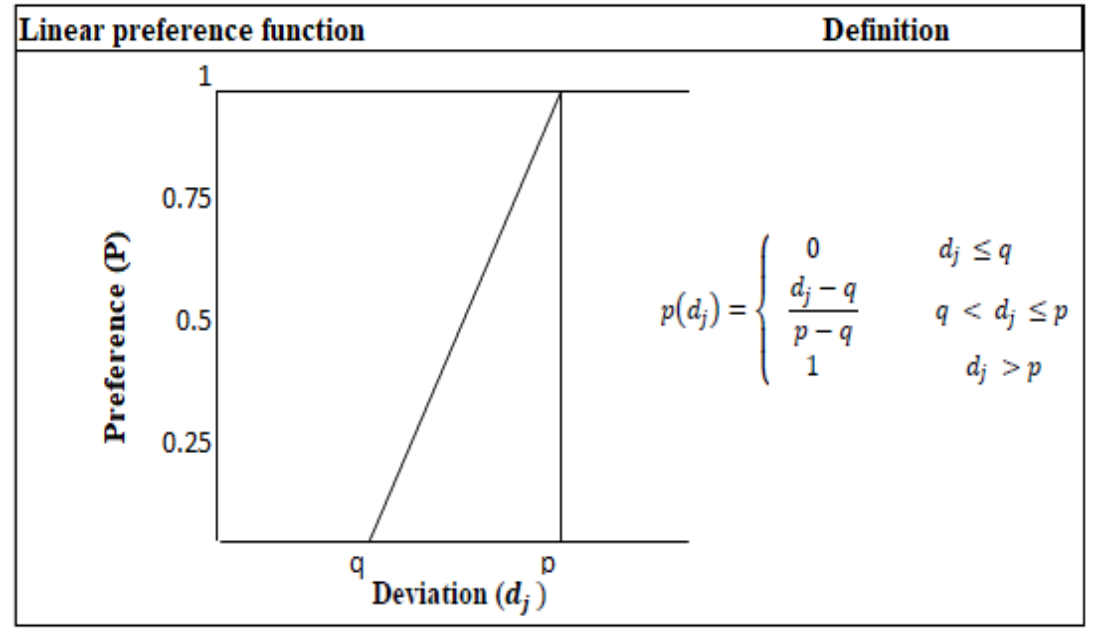

Figure 1. Linear preference function

\subsubsection{The ELECTRE method.}

The ELECTRE method was first proposed by Roy [30] in 1991. The method is based upon outranking concept whereby an alternative $a_{1}$ outranks another alternative $a_{2}$ with enough fact exists to declare that $a_{1}$ is as good as $a_{2}$ and good reasons to reject such facts do not exist. The available versions of ELECTRE are: ELECTRE I, II, III, IV, IS and TRI [31]. The present study ELECTRE III is selected for ranking the alternatives as this method provides an advantage of the direct participation of decision maker and a possibility to analyze both qualitative and quantitative criteria [32]-[34].

Let alternatives $\mathrm{A}=\left(\mathrm{a}_{1}, a_{2}, \ldots, a_{m}\right)$ are assess for a finite $\mathrm{n}$ number of criteria $\left(\mathrm{g}_{1}, g_{2}, \ldots, g_{n}\right) ; g_{j}\left(a_{j}\right)$ represents the performance of the alternative a $\in$ A for the criteria $g_{j}(j=1,2, \ldots, \mathrm{n})$. The ranking procedure of the ELECTRE III model requires to define the threshold function. Let the indifference and threshold for the $j^{t h}$ criteria are represented $q_{j}$ and $p_{j}$ respectively [35].

If $g\left(a_{1}\right) \geq g\left(a_{2}\right)$, then,

$$
\begin{aligned}
& g\left(a_{1}\right)>g\left(a_{2}\right)+p \Leftrightarrow a_{1} P a_{2} \\
& g\left(a_{2}\right)+q<g\left(a_{1}\right)<p \Leftrightarrow a_{1} Q a_{2}
\end{aligned}
$$




$$
g\left(a_{2}\right)<g\left(a_{1}\right)<g\left(a_{2}\right)+q \Leftrightarrow a_{1} I a_{2}
$$

where $\mathrm{P}$ denotes a strong preference, Q denotes a weak preference, I denote an indifference and $g\left(a_{1}\right)$ is the criteria value of the alternative $a_{1}$.

The ELECTRE III ranking calculations involve following steps:

(i) The concordance index $C\left(a_{1}, a_{2}\right)$ is computed for each pair of alternatives:

$$
C_{j}\left(a_{1}, a_{2}\right)=\frac{\sum_{j=1}^{n} w_{j} C_{j}\left(a_{1}, a_{2}\right)}{\sum_{j=1}^{n} w_{j}}
$$

where $C_{j}\left(a_{1}, a_{2}\right)$ is the outranking degree of the alternative $a_{1}$ and $a_{2}$, under criteria $j$

$$
C_{j}\left(a_{1}, a_{2}\right)=\left\{\begin{array}{l}
0 \text { if } g_{j}\left(a_{2}\right)-g_{j}\left(a_{1}\right) \geq p_{j} \\
1 \text { if } g_{j}\left(a_{2}\right)-g_{j}\left(a_{1}\right) \leq q_{j} \\
p_{j}+g_{j}\left(a_{1}\right)-g_{j}\left(a_{2}\right) / p_{j}-q_{j}
\end{array}\right.
$$

Thus $0 \leq C_{j}\left(a_{1}, a_{2}\right) \leq 1$.

The relation between $q_{j}, p_{j}$ and $v_{j}$ is as (25).

$$
q_{j}<p_{j}<v_{j}
$$

The veto threshold $(v)$ allows the possibility of $a_{1} S a_{2}$ i.e outranking to be refused totally if, for anyone criteria $j, g_{j}\left(a_{2}\right)>g_{j}\left(a_{1}\right)+v_{j}$.

(ii) The discordance index $d\left(a_{1}, a_{2}\right)$ for each criterion is then defined as (26).

$$
d_{j}\left(a_{1}, a_{2}\right)=\left\{\begin{array}{c}
0 \text { if } g_{j}\left(a_{2}\right)-g_{j}\left(a_{1}\right) \leq p_{j} \\
1 \text { if } \operatorname{fg}_{j}\left(a_{2}\right)-g_{j}\left(a_{1}\right) \geq v_{j} \\
g_{j}\left(a_{2}\right)-g_{j}\left(a_{1}\right)-p_{j} / v_{j}-p_{j}
\end{array}\right.
$$

Thus $0 \leq d_{j}\left(a_{1}, a_{2}\right) \leq 1$

(iii) Finally, the degree of outranking is defined by (27).

$$
S\left(a_{1}, a_{2}\right)=\left\{\begin{array}{c}
C\left(a_{1}, a_{2}\right) \text { if } d_{j}\left(a_{1}, a_{2}\right) \leq C\left(a_{1}, a_{2}\right) \forall j \in J \\
C\left(a_{1}, a_{2}\right) \times \prod_{j \in J\left(a_{1}, a_{2}\right)} \frac{1-d_{j}\left(a_{1}, a_{2}\right)}{1-C\left(a_{1}, a_{2}\right)} \text { otherwise }
\end{array}\right.
$$

Where $J\left(a_{1}, a_{2}\right)$ is the set of the criteria for which $d_{j}\left(a_{1}, a_{2}\right)>C\left(a_{1}, a_{2}\right)$.

(iv) For complete ranking in ELECTRE III method, the present study used the procedure adopted in [36].

This procedure requires to calculate the concordance credibility degree, the discordance credibility degree, and the net credibility degree:

(a) The concordance credibility degree is defined as (28).

$$
\emptyset^{+}\left(a_{i}\right)=\sum_{b_{i} \in A} S\left(a_{i}, b_{i}\right), \forall a_{i} \in A
$$

The concordance credibility degree measures the outranking character of $a_{i}$ i.e. how $a_{i}$ dominates all other alternatives of $A$.

(b) The discordance credibility degree is defined as (29).

$$
\emptyset^{-}\left(a_{1}\right)=\sum_{b_{i} \in A} S\left(b_{i}, a_{i}\right) \quad \forall a_{i} \in A
$$

(c) The net credibility degree is then calculated as (30).

$$
\emptyset\left(a_{1}\right)=\emptyset^{+}\left(a_{1}\right)-\emptyset^{-}\left(a_{1}\right)
$$


The high value of the net credibility degree represents higher preference of the alternative $A_{i}$ over other alternatives. Hence the ranking of alternatives is done based on the value of the net credibility degree.

\section{SUSTAINABILITY ASSESSMENT AND RANKING OF ALTERNATIVES}

\subsection{Selection of alternatives}

The first step in MCDM is the selection of the alternatives. The 14 major hydropower projects from various regions of India are carefully selected as alternatives with a focus on projects having installed capacity more than $200 \mathrm{MW}$, displacement or resettlement of more than 4000 people and having a large reservoir to make the problem more objective. Table 2 presents the list of selected hydropower projects.

Table 2. List of selected hydropower projects

\begin{tabular}{cccc}
\hline Alternatives & Hydro power project & State & Installed capacity (MW) \\
\hline$A_{1}$ & Balimela & Odisha & 510 \\
$A_{2}$ & Bhakra & Himachal Pradesh & 1325 \\
$A_{3}$ & Hirakud & Odisha & 347 \\
$A_{4}$ & Indira Sagar & Madhya Pradesh & 1000 \\
$A_{5}$ & Pong & Himachal Pradesh & 396 \\
$A_{6}$ & Rengali & Odisha & 250 \\
$A_{7}$ & Rihand & Uttar Pradesh & 300 \\
$A_{8}$ & Sardar Sarovar & Gujrat & 1450 \\
$A_{9}$ & Sharavathi & Karnataka & 1035 \\
$A_{10}$ & Srisailam & Telangana & 770 \\
$A_{11}$ & Tehri & Uttarakhand & 1000 \\
$A_{12}$ & Ukai & Gujrat & 300 \\
$A_{13}$ & Upper Indravati & Odisha & 600 \\
$A_{14}$ & Upper Kolab & Odisha & 320 \\
\hline
\end{tabular}

\subsection{Selection of evaluation criteria}

The second step is very critical under MCDM approach i.e. identification and selection of criteria to compare the alternatives with respect to a particular perspective. For sustainability evaluation of renewable energy generation technologies, ranges of criteria should be considered [37]. The accessible information in terms of quantitative and qualitative data of alternatives will decide the selection of number of criteria. The criteria selected in the present study for ranking of hydropower projects based on sustainability are, installed capacity, average electricity generation, capacity factor, cost of generation, land use, displacement of people, safety and social benefits. Table 3 presents the summary of selected criteria, preference criteria to be maximum or minimum and studies undertaken which supports the selection of these criteria. The study takes into account all four types of criteria which are well known pillars of sustainability i.e., techno-economic, economic, environmental and social as follows:

\subsubsection{Techno-economic}

The criteria selected in this type are installed capacity, annual energy production, and capacity factor. Mostly in the available literature, these criteria are merged with the economic criteria [37], [38], whereas some have considered them in technical or generation aspects [8], [13]. Therefore, in the present study, these selected criteria have been considered as techno-economic criteria.

- Installed capacity: In the present study installed capacity is a direct indication of the potential to generate the power.

- Electricity generation per year: Annual energy production directly improves the economy of power projects.

- Capacity factor: The capacity factor is defined as the ratio of the total actual energy generated over a definite period, to the energy that would have been generated if the power plant had operated continuously at the maximum rating. Capacity factor shows the power project capacity to produce energy without any kind of defect or break down.

\subsubsection{Economic}


This criterion represents the cost and profit of the hydropower projects with respect to long term success. Cost of generation: It is a major criterion regards to the economic sustainability of the project. An economically sound project because of its low generation cost offers good investment opportunities [6].

\subsubsection{Environmental}

This criterion represents the project's environmental affinity with the surrounding region and ecology. Land use: The land use in the form of the reservoir may destroy the ecosystem. It results in greenhouse gas emissions, soil erosion, silt deposition, obstruction to fish migration. The land coverage in the form flooding area of dam cause loss of farming plots, loss of spiritual places and increase infectious disease [39].

\subsubsection{Social}

The social criteria indicate the life of local communities affected or benefited by the construction of hydropower projects. Public perception plays an important role in the deployment of hydropower projects [40].

- Displacement and resettlement: The main social impact of the construction of large hydropower dam reservoirs are the displacement and resettlement of affected communities. This forced displacement and the resettling process do not guarantee the same life that existed before. Hence from a sustainability point of view resettlement or displacement should be minimum.

- Safety: As far as the safety of hydropower projects is concerned, the failure of dams caused by earthquakes still remains a serious threat as they are capable to completely break the dam with the energy released from the event [41]. Based on the historical seismic activity, the regions of India have been classified into four seismic zones by the Bureau of Indian Standards. These are zone II (low-intensity zone), zone III (moderate intensity zone), zone IV (severe intensity zone) and zone V (very severe intensity zone). Based on the zone on which selected dams fall, safety is marked in the scale of (1-4). The dams which fall on zone II have been scaled 4 i.e safer compared to other zones. Similarly scaling for zone III is 3 , zone IV is 2 and zone V is 1 respectively.

- Social benefits: The benefits such as irrigation, flood control, recreation along with generation are also the major criteria from a sustainability point of view [37], [39]. The selected hydropower projects were scaled on (1-4) based on the benefits they are providing. For example, the hydropower projects which serve the propose of only power generation were scaled as 1 and hydropower projects which serve the purpose of generation, irrigation, flood control, and recreation was scaled as 4 respectively.

Table 3. Summary of selected criteria

\begin{tabular}{llllc}
\hline \multicolumn{1}{c}{ Criterion } & \multicolumn{1}{c}{ Type } & \multicolumn{1}{c}{ Unit } & Preference Criterion & Reference study \\
\hline Installed capacity $\left(C_{1}\right)$ & Techno-economic & MW & Maximum & {$[8],[38]$} \\
Electricity generation per year $\left(C_{2}\right)$ & Techno-economic & MU/year & Maximum & {$[8],[13]$} \\
Capacity factor $\left(C_{3}\right)$ & Techno-economic & percentage & Maximum & {$[42]$} \\
Cost of generation $\left(C_{4}\right)$ & Economic & Paisa/kWh & Minimum & {$[8],[37]$} \\
Land use $\left(C_{5}\right)$ & Environmental & hector & Minimum & {$[9],[13],[37]$} \\
Displacement $\left(C_{6}\right)$ & Social & Persons & Minimum & {$[8],[9],[37]$} \\
Safety $\left(C_{7}\right)$ & Social & Qualitative $(1-4)$ & Maximum & {$[8]$} \\
Social benefits $\left(C_{8}\right)$ & Social & Qualitative (1-4) & Maximum & {$[2],[37]$} \\
\hline
\end{tabular}

\subsection{Weights calculation of criteria by AHP}

The criteria weights by AHP methods are calculated per the steps mentioned in section 2.1. Table 4 presents the value of weights. Using steps vi-viii mentioned in section 2.1, the value of $C R$ obtained is 0.0578 which is acceptable under limit $\mathrm{CR} \leq 0.1$. Therefore, there exist the consistency in weights and can be used for the sustainability assessment. 


$$
B=\left[\begin{array}{cccccccc}
1 & 1 / 5 & 1 / 5 & 1 / 7 & 1 / 3 & 1 / 3 & 3 & 1 / 3 \\
5 & 1 & 1 & 1 & 3 & 3 & 5 & 3 \\
5 & 1 & 1 & 1 / 3 & 3 & 3 & 5 & 3 \\
3 & 1 / 3 & 1 / 3 & 1 / 5 & 1 & 1 & 3 & 3 \\
3 & 1 / 3 & 1 / 3 & 1 / 5 & 1 & 1 & 3 & 3 \\
7 & 1 & 3 & 1 & 5 & 5 & 5 & 7 \\
1 / 3 & 1 / 5 & 1 / 5 & 1 / 5 & 1 / 3 & 1 / 3 & 1 & 1 / 3 \\
3 & 1 / 3 & 1 / 3 & 1 / 7 & 1 / 3 & 1 / 3 & 3 & 1
\end{array}\right]
$$

Table 4. Criteria weights calculated using AHP

\begin{tabular}{ccccc}
\hline Criterion & GM & Criterion weight $(\mathrm{W})$ & $\mathrm{X}=\mathrm{B} . \mathrm{W}$ & $\mathrm{CV}$ \\
\hline$C_{1}$ & 0.3984 & 0.0368 & 0.3236 & 8.7925 \\
$C_{2}$ & 2.2577 & 0.2086 & 1.7208 & 8.25 \\
$C_{3}$ & 1.968 & 0.1818 & 1.5107 & 8.3087 \\
$C_{4}$ & 3.4122 & 0.3152 & 2.7248 & 8.6436 \\
$C_{5}$ & 0.9381 & 0.0867 & 0.7296 & 8.4176 \\
$C_{6}$ & 0.9381 & 0.0867 & 0.7296 & 8.4176 \\
$C_{7}$ & 0.3157 & 0.0292 & 0.2587 & 8.8694 \\
$C_{8}$ & 0.5958 & 0.055 & 0.486 & 8.8289 \\
& \multicolumn{5}{c}{$\lambda_{\max }=\operatorname{Avg}(\mathrm{CV}) 8.5660$} \\
\hline
\end{tabular}

\subsection{Sustainability ranking of hydropower projects}

The values of the selected criterion for hydropower projects (alternatives) are presented in Table 5 along with weights calculated using AHP as shown in Table 4. Table 5 will be the input decision matrix to all the methods employed for sustainability ranking of hydropower projects wherein $C_{1}, C_{2}, C_{3}, C_{7}, C_{8}$ are beneficial criteria (larger the better) and $\mathrm{C}_{4}, \mathrm{C}_{5}, \mathrm{C}_{6}$ are cost criteria (smaller the better). The ranking of hydropower projects is based on the following selected methods:

Table 5. Values for selected criterion for each selected alternative ${ }^{\mathrm{a}}$

\begin{tabular}{|c|c|c|c|c|c|c|c|c|}
\hline & $C_{l}$ & $C_{2}$ & $C_{3}$ & $C_{4}$ & $C_{5}$ & $C_{6}$ & $C_{7}$ & $C_{8}$ \\
\hline$A_{l}$ & 510 & 1240.93 & 28 & 88.22 & 17496 & 10000 & 2 & 4 \\
\hline$A_{2}$ & 1325 & 6117 & 53 & 33.07 & 16600 & 36000 & 3 & 2 \\
\hline$A_{3}$ & 347 & 564.49 & 19 & 127.64 & 74300 & 11000 & 2 & 3 \\
\hline$A_{4}$ & 1000 & 2542.72 & 29 & 243.86 & 90820 & 80500 & 2 & 3 \\
\hline$A_{5}$ & 396 & 1315.48 & 38 & 23.62 & 29000 & 150000 & 2 & 2 \\
\hline$A_{6}$ & 250 & 710.1 & 32 & 108.09 & 414500 & 80000 & 3 & 4 \\
\hline$A_{7}$ & 300 & 572.11 & 22 & 55 & 46900 & 60000 & 2 & 3 \\
\hline$A_{8}$ & 1450 & 2909 & 23 & 205 & 37590 & 320000 & 2 & 3 \\
\hline$A_{9}$ & 1035 & 5147.47 & 57 & 27.69 & 5921 & 12500 & 1 & 3 \\
\hline$A_{10}$ & 770 & 1141.04 & 17 & 398.2 & 60629 & 100000 & 2 & 4 \\
\hline$A_{11}$ & 1000 & 2967.13 & 34 & 587 & 4200 & 100000 & 2 & 2 \\
\hline$A_{12}$ & 300 & 708.73 & 27 & 33 & 60000 & 80000 & 3 & 3 \\
\hline$A_{13}$ & 600 & 2597.23 & 49 & 80.42 & 11000 & 26505 & 2 & 4 \\
\hline$A_{14}$ & 320 & 702.7 & 25 & 49.84 & 11350 & 15895 & 2 & 4 \\
\hline Weight $(W j)$ & 0.0368 & 0.2086 & 0.1818 & 0.3152 & 0.0867 & 0.0867 & 0.0292 & 0.055 \\
\hline
\end{tabular}

$\mathrm{C}_{7}, \mathrm{C}_{8}$ ) is calculated as discussed in section 3.2 using data from the website of specific hydropower projects.

\subsubsection{The TOPSIS method}

As per the steps elaborated in section 2.2.1, Table 5 is the input decision matrix for TOPSIS analysis. The normalized decision matrix is calculated using (8). Further the rank of alternatives is obtained by following the steps iii-vi as mentioned in section 2.2.1. Table 6 presents the results obtained by TOPSIS method. Lastly, according to the value of $R i$, the ranking is given to alternatives as $A_{2}-A_{9}-A_{13}-A_{5}-A_{1}-A_{14}$ $A_{12}-A_{7}-A_{3}-A_{8}-A_{4}-A_{6}-A_{10}-A_{11}$. Hence it can be concluded that hydropower project $A_{2}$ i.e. Bhakra and $A_{9}$ i.e. Sharavathi are most sustainable hydropower projects under the given eight criteria. 
Table 6. TOPSIS method results

\begin{tabular}{cccccccccccc}
\hline & $C_{I}$ & $C_{2}$ & $C_{3}$ & $C_{4}$ & $C_{5}$ & $C_{6}$ & $C_{7}$ & $C_{8}$ & $S_{i}^{+}$ & $S_{i}^{-}$ & $R_{i}$ \\
\hline$A_{1}$ & 0.0063 & 0.0257 & 0.0394 & 0.0343 & 0.0034 & 0.0021 & 0.0071 & 0.0182 & 0.1126 & 0.2201 & 0.6616 \\
$A_{2}$ & 0.0165 & 0.1269 & 0.0745 & 0.0129 & 0.0032 & 0.0076 & 0.0106 & 0.0091 & 0.0129 & 0.2685 & 0.9543 \\
$A_{3}$ & 0.0043 & 0.0117 & 0.0267 & 0.0497 & 0.0145 & 0.0023 & 0.0071 & 0.0137 & 0.1348 & 0.2015 & 0.5993 \\
$A_{4}$ & 0.0124 & 0.0527 & 0.0408 & 0.0949 & 0.0177 & 0.0169 & 0.0071 & 0.0137 & 0.1223 & 0.1626 & 0.5707 \\
$A_{5}$ & 0.0049 & 0.0273 & 0.0534 & 0.0092 & 0.0056 & 0.0315 & 0.0071 & 0.0091 & 0.1086 & 0.2369 & 0.6857 \\
$A_{6}$ & 0.0031 & 0.0147 & 0.0450 & 0.0421 & 0.0807 & 0.0168 & 0.0106 & 0.0182 & 0.1474 & 0.1946 & 0.5691 \\
$A_{7}$ & 0.0037 & 0.0119 & 0.0309 & 0.0214 & 0.0091 & 0.0126 & 0.0071 & 0.0137 & 0.1273 & 0.2260 & 0.6396 \\
$A_{8}$ & 0.0180 & 0.0603 & 0.0323 & 0.0798 & 0.0073 & 0.0672 & 0.0071 & 0.0137 & 0.1265 & 0.1738 & 0.5787 \\
$A_{9}$ & 0.0129 & 0.1068 & 0.0801 & 0.0108 & 0.0012 & 0.0026 & 0.0035 & 0.0137 & 0.0225 & 0.2650 & 0.9219 \\
$A_{10}$ & 0.0096 & 0.0237 & 0.0239 & 0.1550 & 0.0118 & 0.0210 & 0.0071 & 0.0182 & 0.1888 & 0.1121 & 0.3726 \\
$A_{11}$ & 0.0124 & 0.0616 & 0.0478 & 0.2285 & 0.0008 & 0.0210 & 0.0071 & 0.0091 & 0.2321 & 0.1080 & 0.3176 \\
$A_{12}$ & 0.0037 & 0.0147 & 0.0380 & 0.0128 & 0.0117 & 0.0168 & 0.0106 & 0.0137 & 0.1222 & 0.2326 & 0.6555 \\
$A_{13}$ & 0.0075 & 0.0539 & 0.0689 & 0.0313 & 0.0021 & 0.0056 & 0.0071 & 0.0182 & 0.0780 & 0.2297 & 0.7465 \\
$A_{14}$ & 0.0040 & 0.0146 & 0.0351 & 0.0194 & 0.0022 & 0.0033 & 0.0071 & 0.0182 & 0.1223 & 0.2328 & 0.6556 \\
$V_{j}^{+}$ & 0.0180 & 0.1269 & 0.0801 & 0.2285 & 0.0807 & 0.0672 & 0.0106 & 0.0182 & & & \\
$V_{j}^{-}$ & 0.0031 & 0.0117 & 0.0239 & 0.0092 & 0.0008 & 0.0021 & 0.0035 & 0.0091 & & & \\
\hline
\end{tabular}

\subsubsection{The PROMETHEE method}

As per the methodology described in section 2.2.3, Table 7 presents the selected preference function and the values of thresholds i.e., $q$ and $p$ for each criterion. The values of outranking flows i.e., $\emptyset^{+}, \emptyset^{-}$and $\emptyset^{-}$ is calculated using (17), (18) and (19) and alternatives are ranked according to the value of $\emptyset$ as presented in Table 8 .

Table 7. Selected preference function and threshold parameters

\begin{tabular}{cccc}
\hline \multirow{2}{*}{ Criterion } & \multirow{2}{*}{ Preference function } & \multicolumn{2}{c}{ Threshold } \\
& & $q$ & $p$ \\
\hline$C_{1}$ & Linear & 100 & 200 \\
$C_{2}$ & Linear & 300 & 2000 \\
$C_{3}$ & Linear & 5 & 15 \\
$C_{4}$ & Linear & 20 & 100 \\
$C_{5}$ & Linear & 2000 & 10000 \\
$C_{6}$ & Linear & 2000 & 10000 \\
$C_{7}$ & Usual & n/a & n/a \\
$C_{8}$ & Usual & n/a & n/a \\
\hline
\end{tabular}

Table 8. Outranking flow and ranking pattern of alternatives

\begin{tabular}{ccclc}
\hline Alternative & \multicolumn{1}{c}{$\emptyset^{+}$} & \multicolumn{1}{c}{$\emptyset^{-}$} & \multicolumn{1}{c}{$\emptyset$} & Rank \\
\hline$A_{1}$ & 0.6933 & 0.0628 & 0.6306 & 5 \\
$A_{2}$ & 0.6739 & 0.0992 & 0.5747 & 2 \\
$A_{3}$ & 0.5401 & 0.1357 & 0.4044 & 13 \\
$A_{4}$ & 0.307 & 0.2075 & 0.0995 & 12 \\
$A_{5}$ & 0.3092 & 0.2292 & 0.08 & 6 \\
$A_{6}$ & 0.3332 & 0.305 & 0.0282 & 9 \\
$A_{7}$ & 0.2512 & 0.3036 & -0.0525 & 8 \\
$A_{8}$ & 0.2236 & 0.3333 & -0.1097 & 11 \\
$A_{9}$ & 0.2261 & 0.3958 & -0.1697 & 1 \\
$A_{10}$ & 0.2947 & 0.5149 & -0.2202 & 14 \\
$A_{11}$ & 0.2646 & 0.4982 & -0.2336 & 10 \\
$A_{12}$ & 0.2469 & 0.4899 & -0.243 & 7 \\
$A_{13}$ & 0.1875 & 0.4699 & -0.2824 & 3 \\
$A_{14}$ & 0.1287 & 0.6349 & -0.5062 & 4 \\
\hline
\end{tabular}

\subsubsection{The ELECTRE method}

The ranking procedure of the ELECTRE III method requires to define the $q, p$ and $v$ thresholds for the criteria. The selected values of thresholds for criteria are presented in Table 9. Table 10 presents the $S\left(a_{1}, a_{2}\right)$, concordance credibility $\left(\emptyset^{+}\right)$, discordance credibility $\left(\emptyset^{-}\right)$and net credibility $(\varnothing)$ calculated using (28), (29) and (30) and finally the ranking to the alternatives is given according to the value of $(\varnothing)$. 
Table 9. Selected values of thresholds for criteria

\begin{tabular}{cccc}
\hline Criterion & $q$ & $p$ & $v$ \\
\hline$C_{1}$ & 100 & 200 & 400 \\
$C_{2}$ & 300 & 2000 & 4000 \\
$C_{3}$ & 5 & 15 & 30 \\
$C_{4}$ & 20 & 100 & 200 \\
$C_{5}$ & 2000 & 10000 & 20000 \\
$C_{6}$ & 2000 & 10000 & 20000 \\
$C_{7}$ & 0 & 1 & 2 \\
$C_{8}$ & 0 & 1 & 2 \\
\hline
\end{tabular}

Table 10. The degree of outranking and ranking of alternatives

\begin{tabular}{|c|c|c|c|c|c|c|c|c|c|c|c|c|c|c|c|}
\hline & $\mathrm{A}_{1}$ & $\mathrm{~A}_{2}$ & $\mathrm{~A}_{3}$ & $\mathrm{~A}_{4}$ & $\mathrm{~A}_{5}$ & $\mathrm{~A}_{6}$ & $\mathrm{~A}_{7}$ & $\mathrm{~A}_{8}$ & $\mathrm{~A}_{9}$ & $\mathrm{~A}_{10}$ & $\mathrm{~A}_{11}$ & $\mathrm{~A}_{12}$ & $\mathrm{~A}_{13}$ & $\mathrm{~A}_{14}$ & $\emptyset^{+}$ \\
\hline $\mathrm{A}_{2}$ & 0 & 1 & 0 & 0.945 & 1 & 0 & 0.945 & 0.93 & 0 & 0 & 0.91 & 0.94 & 0 & 0 & 6.68 \\
\hline $\mathrm{A}_{3}$ & 0 & 0 & 1 & 0 & 0 & $\begin{array}{c}0.74 \\
04\end{array}$ & 0 & 0 & 0 & 0 & 0 & $\begin{array}{c}0.53 \\
55\end{array}$ & 0 & 0 & 2.31 \\
\hline $\mathrm{A}_{4}$ & 0 & 0 & 0 & 1 & 0 & $\begin{array}{c}0.60 \\
06\end{array}$ & 0 & 0 & 0 & 0 & 0 & 0 & 0 & 0 & 1.60 \\
\hline $\mathrm{A}_{6}$ & 0 & 0 & 0 & 0 & 0 & 1 & 0 & 0 & 0 & 0 & 0 & 0 & 0 & 0 & 1.00 \\
\hline $\mathrm{A}_{7}$ & 0 & 0 & 0 & 0 & $\begin{array}{c}0.36 \\
11\end{array}$ & $\begin{array}{c}0.82 \\
49\end{array}$ & 1 & 0 & 0 & 0 & 0 & $\begin{array}{c}0.96 \\
29\end{array}$ & 0 & 0 & 3.15 \\
\hline $\mathrm{A}_{8}$ & 0 & 0 & 0 & 0 & 0 & 0 & 0 & 1 & 0 & 0 & 0 & 0 & 0 & 0 & 1.00 \\
\hline $\mathrm{A}_{9}$ & 0.91 & 0 & 0.97 & 0.970 & 0.97 & 0 & 0.970 & 0 & 1 & 0.91 & 0.97 & 0 & 0.91 & 0.91 & 9.51 \\
\hline $\mathrm{A}_{12}$ & 0 & 0 & 0 & 0 & 0 & 0 & 0 & 0 & 0 & 0 & 0 & 1 & 0 & 0 & 1.95 \\
\hline $\mathrm{A}_{13}$ & 0.91 & 0 & 0.91 & 0 & 0.85 & 0.97 & 0.978 & 0 & 0 & 0.97 & 0 & 0.86 & 1 & 0.87 & 8.34 \\
\hline & 33 & & 33 & & 5 & 08 & 6 & & & 42 & & 28 & & 16 & \\
\hline $\mathrm{A}_{14}$ & 0.89 & 0 & 0.96 & 0 & 0.79 & 0.93 & 1 & 0 & 0 & 0 & 0 & 0.97 & 0.56 & 1 & 7.13 \\
\hline & 54 & & 86 & & 17 & 44 & & & & & & 08 & 56 & & \\
\hline$\varnothing$ & 3.72 & 1.00 & 4.85 & 4.85 & 5.71 & 7.02 & 5.84 & 1.94 & 1.00 & 3.85 & 2.88 & 6.11 & 3.12 & 3.67 & \\
\hline$\varnothing$ & 4.25 & 5.68 & -2.55 & -1.33 & -4.71 & -6.02 & -2.69 & -0.94 & 8.51 & -2.84 & -1.88 & -4.16 & 5.22 & 3.46 & \\
\hline Rank & 4 & 2 & 9 & 7 & 13 & 14 & 10 & 6 & 1 & 11 & 8 & 12 & 3 & 5 & \\
\hline
\end{tabular}

\section{RESULTS AND DISCUSSION}

Table 11 presents the ranking of hydropower projects obtained by TOPSIS, PROMETHEE II and ELECTRE III using eight sustainability criteria. Comparing the ranking of hydropower projects obtained using these four MCDM methods shows that alternative $A_{9}$ i.e., Sharavathi hydropower project obtained top ranking by PROMETHEE, and ELECTRE, whereas by TOPSIS it is on the second rank. But when comparing the values of $R_{i}$ in TOPSIS, the value of $R_{i}$ is very close for $A_{2}$ and $A_{9}$. Hence it can be concluded that Sharavathi hydropower $\left(A_{9}\right)$ is evaluated as the most sustainable project under eight selected criteria for assigned weights. While comparing the complete ranking of all 14 hydropower projects, the three hydropower projects i.e., Sharavathi $\left(A_{9}\right)$, Bhakra $\left(A_{2}\right)$ and Upper Indravati $\left(A_{13}\right)$ are on top three ranking by all four methods. All the methods gave somewhat different results with respect to the ranking position from 4-14 of the alternatives. The inconsistencies observed in the results of these methods are because of the differences in the calculation techniques, different interpretation of the criteria weights and the impact of the threshold values in the methods.

TOPSIS is based on the concept of compromise solution but their method of normalization is different. The PROMETHEE II and ELECTRE III are outranking methods which are based on the pairwise comparison and also allows the decision maker to express the preference in the form of threshold parameters. All the three MCDM methods are well adapted for ranking of hydropower projects considering both quantitative and qualitative features of criteria. The results produced by the different methods are usually different even considering the same problem with same input data. The need to take into account the factors like social, environmental, economic and technological in decision making for sustainability ranking of hydropower projects, make the process more complex. Hence MCDM methods have proved to be very helpful when there is a difficulty in selecting the best alternative while considering conflicting criteria and incomparable units. For future work, the proposed methods with the fuzzy environment can be applied to rank the hydropower projects and results can be compared. 
Table 11. Ranking of hydropower projects from proposed methods

\begin{tabular}{cccc}
\hline Ranking & TOPSIS & PROMETHEE & ELECTRE \\
\hline 1 & $A_{2}$ & $A_{9}$ & $A_{9}$ \\
2 & $A_{9}$ & $A_{2}$ & $A_{2}$ \\
3 & $A_{13}$ & $A_{13}$ & $A_{13}$ \\
4 & $A_{5}$ & $A_{14}$ & $A_{1}$ \\
5 & $A_{1}$ & $A_{1}$ & $A_{14}$ \\
6 & $A_{14}$ & $A_{5}$ & $A_{8}$ \\
7 & $A_{12}$ & $A_{12}$ & $A_{4}$ \\
8 & $A_{7}$ & $A_{7}$ & $A_{11}$ \\
9 & $A_{3}$ & $A_{6}$ & $A_{3}$ \\
10 & $A_{8}$ & $A_{11}$ & $A_{7}$ \\
11 & $A_{4}$ & $A_{8}$ & $A_{10}$ \\
12 & $A_{6}$ & $A_{4}$ & $A_{12}$ \\
13 & $A_{10}$ & $A_{3}$ & $A_{5}$ \\
14 & $A_{11}$ & $A_{10}$ & $A_{6}$ \\
\hline
\end{tabular}

\section{CONCLUSION}

The present study demonstrates the effectiveness of TOPSIS, PROMETHEE II, and ELECTRE III methods to rank the hydropower projects based on eight sustainability criteria. AHP method is used to calculate the criteria weights. All these four methods are well adapted for sustainability assessment and ranking of hydropower projects considering conflicting criteria. The hydropower projects in the preference i.e., Sharavathi $\left(A_{9}\right)$, Bhakra $\left(A_{2}\right)$ and Upper Indravati $\left(A_{13}\right)$ are ranked to be the most sustainable projects by the proposed methods. There is inconsistency in the complete ranking obtained by all these four methods even considering the same problem with same data is due to differences in the calculation techniques, the impact of the threshold values and the different interpretation of the criteria weights in the methods. Hence no single method can be categorized as best or worst, it depends on a certain application where some technique fits better. The study recommends PROMETHEE II and ELECTRE III for ranking since their flexibility allows the decision maker to express precisely the preferences for selecting the best alternative.

The application of MCDM techniques in ranking different renewable energy technologies and projects while considering several criteria and objective simultaneously has proved to be a reliable and realistic approach. Hence the paper highlights the potential of MCDM methods for multi-criteria analysis of any power project with stochastic nature (i.e., wind, solar, geothermal.) using quantitative as well as qualitative criteria.

\section{REFERENCES}

[1] S. Rehman, L. M. Al-Hadhrami and M. M. Alam, "Pumped hydro energy storage system: A technological review," Renewable and Sustainable Energy Reviews, vol. 44, pp. 586-598, 2015, doi: 10.1016/j.rser.2014.12.040.

[2] K. Kaygusuz, "The role of hydropower for sustainable energy development," Energy Sources, Part B, vol. 4, no. 4, pp. 365-376, 2009, doi: 10.1080/15567240701756889.

[3] M. Capik, A. O. Y1lmaz and I. Cavusoglu, "Hydropower for sustainable energy development in Turkey: The small hydropower case of the Eastern Black Sea Region," Renewable and Sustainable Energy Reviews, vol. 16, no. 8, pp. 6160-6172, 2012, doi: 10.1016/j.rser.2012.06.005.

[4] A. Shaktawat, and S. Vadhera, "Risk management of hydropower projects for sustainable development: A review," Environment, Development and Sustainability, vol. 23, pp. 45-76, 2020, doi: 10.1007/s10668-020-00607-2.

[5] A. T. de Almeida, P. S. Moura, A. S. Marques, and J. L. de Almeida, "Multi-impact evaluation of new medium and large hydropower plants in Portugal centre region," Renewable and Sustainable Energy Reviews, vol. 9, no. 2, pp. 149-167, 2005, doi: 10.1016/j.rser.2004.01.015.

[6] D. Kumar and S. S. Katoch, "Sustainability indicators for run of the river (RoR) hydropower projects in hydro rich regions of India," Renewable and Sustainable Energy Reviews, vol. 35, pp. 101-108, 2014, doi: 10.1016/j.rser.2014.03.048.

[7] N. Mladineo, J. Margeta, J. P. Brans and B. Mareschal, "Multicriteria ranking of alternative locations for small scale hydro plants," European journal of Operational Reasearch, vol. 31, no. 2, pp. 215-222, 1978, doi: 10.1016/0377-2217(87)90025-7.

[8] T. Supriyasilp, K. Pongput and T. Boonyasirikul, "Hydropower development priority using MCDM method," Energy Policy, vol. 37, no. 5, pp. 1866-1875, 2009, doi: 10.1016/j.enpol.2009.01.023.

[9] M. Rosso, M. Bottero, S. Pomarico, S. La Ferlita and E. Comino, "Integrating multicriteria evaluation and stakeholders analysis for assessing hydropower projects," Energy Policy, vol. 67, pp. 870-881, 2014, doi: 10.1016/j.enpol.2013.12.007.

[10] H. Aras, S. Erdoğmuş and E. Koç, "Multi-criteria selection for a wind observation station location using analytic hierarchy process," Renewable Energy, vol. 29, no. 8, pp. 1383-1392, 2004, doi: 10.1016/j.renene.2003.12.020. 
[11] M. Goumas and V. Lygerou, "An extension of the PROMETHEE method for decision making in fuzzy environment: Ranking of alternative energy exploitation projects," European Journal of Operational Research, vol. 123, no. 3, pp. 606-613, 2000, doi: 10.1016/S0377-2217(99)00093-4.

[12] D. A. Haralambopoulos and H. Polatidis, "Renewable energy projects: structuring a multi-criteria group decisionmaking framework," Renewable Energy, vol. 28, pp. 961-973, 2003, doi: 10.1016/S0960-1481(02)00072-1.

[13] M. Troldborg, S. Heslop and R. L. Hough, "Assessing the sustainability of renewable energy technologies using multi-criteria analysis: Suitability of approach for national-scale assessments and associated uncertainties," Renewable and Sustainable Energy Reviews, vol. 39, pp. 1173-1184, 2014, doi: 10.1016/j.rser.2014.07.160.

[14] M. Beccali, M. Cellura and M. Mistretta, "Decision-making in energy planning. Application of the Electre method at regional level for the diffusion of renewable energy technology," Renewable Energy, vol. 28 no. 13, pp. 20632087, 2003, doi: 10.1016/S0960-1481(03)00102-2.

[15] E. Georgopoulou, D. Lalas and L. Papagiannakis, "A multicriteria decision aid approach for energy planning problems: the case of renewable energy option," European Journal of Operational Research, vol. 103, no. 1, pp. 38-54, 1997, doi: 10.1016/S0377-2217(96)00263-9.

[16] Ü. Şengül, M. Eren, S. E. Shiraz, V. Gezder and A. B. Şengül, "Fuzzy TOPSIS method for ranking renewable energy supply systems in Turkey," Renewable Energy, vol. 75, pp. 617-625, 2015, doi: 10.1016/j.renene.2014.10.045.

[17] F. E. Boran, K. Boran and T. Menlik, "The evaluation of renewable energy technologies for electricity generation in Turkey using intuitionistic fuzzy TOPSIS," Energy Sources, Part B: Economics, Planning, and Policy, vol. 7, no. 1, pp. 81-90, 2012, doi: 10.1080/15567240903047483.

[18] H. Doukas, C. Karakosta and J. Psarras, "A linguistic TOPSIS model to evaluate the sustainability of renewable energy options," International Journal of Global Energy Issues, vol. 32, no. 1/2, pp. 102-118, 2009, doi: 10.1504/IJGEI.2009.027976.

[19] A. Kumar, B. Sah, A. R. Singh, Y. Deng, X. He, P. Kumar and R. C. Bansal, "A review of multi criteria decision making (MCDM) towards sustainable renewable energy development," Renewable and Sustainable Energy Reviews, vol. 69, pp. 596-609, 2017, doi: 10.1016/j.rser.2016.11.191

[20] T.L. Saaty, The Analytic Hierarchy Process, New York: McGraw-Hill International, 1980.

[21] R. V. Rao, Decision making in the manufacturing environment: using graph theory and fuzzy multiple attribute decision making methods, Springer Science \& Business Media, 2007.

[22] C. L. Hwang and K. Yoon, Multiple attribute decision making: Methods and applications. A state of the art survey, New York: Springer, 1981.

[23] İ. Ertuğrul, N. Karakaşoğlu, "Performance evaluation of Turkish cement firms with fuzzy analytic hierarchy process and TOPSIS methods," Expert Systems with Applications, vol. 36, pp. 702-715, 2009, doi: 10.1016/j.eswa.2007.10.014.

[24] R. V. Rao and J. P. Davim, "A decision-making framework model for material selection using a combined multiple attribute decision-making method," The International Journal of Advanced Manufacturing Technology, vol. 35, pp. 751-760, 2008, doi: 10.1007/s00170-006-0752-7.

[25] J. P. Brans, P. Vincke and B. Mareschal, "How to select and how to rank projects: The PROMETHEE method," European Journal of Operational Research, vol. 24, no. 2, pp. 228-38, 1986, doi: 10.1016/0377-2217(86)90044-5.

[26] J. Geldermann, T. Spengler and O. Rentz, "Fuzzy outranking for environmental assessment. Case study: iron and steel making industry," Fuzzy Sets and Systems, vol. 115, no. 1, pp. 45-65, 2000, doi: S0165-0114(99)00021-4.

[27] W. C. Chou, W. T. Lin and C. Y. Lin, "Application of fuzzy theory and PROMETHEE technique to evaluate suitable ecotechnology method: A case study in Shihmen Reservoir Watershed, Taiwan," Ecological Engineering, vol. 31, no. 4, pp. 269-280, 2007, doi: 10.1016/j.ecoleng.2007.08.004.

[28] J. P. Brans and B. Mareschal, "PROMETHEE methods," in Multiple criteria decision analysis: State of the art surveys, New York: Springer, pp. 163-186, 2005.

[29] S. C. Deshmukh, "Preference ranking organization method of enrichment evaluation (PROMETHEE)," International Journal of Engineering Science Invention, vol. 2, no. 11, pp. 28-34, 2003.

[30] B. Roy, "The outranking approach and the foundations of ELECTRE methods," Theory and Decision, Vol. 3, pp. 49-73, 1991, doi: 10.1007/BF00134132

[31] J. J. Peng, J. Q. Wang, J. Wang, L. J. Yang, X. H. Chen, "An extension of ELECTRE to multi-criteria decisionmaking problems with multi-hesitant fuzzy sets," Information Sciences, vol. 307, pp. 113-126, 2015, doi: 10.1016/j.ins.2015.02.030.

[32] M. G. Rogers, M. Bruen, L. Y. Maystre, "ELECTRE and decision support: methods and applications in engineering and infrastructure investment," Springer Science \& Business Media, 2013.

[33] A. S. Milani A. Shanian and C. El-Lahham, "Using different ELECTRE methods in strategic planning in the presence of human behavioral resistance," Journal of Applied Mathematics and Decision Sciences, vol. 2006, pp. 119, 2006, doi: g/10.1155/JAMDS/2006/10936.

[34] S. S. Hashemi, S. H. Hajiagha, E. K. Zavadskas, and H. A. Mahdiraji, "Multicriteria group decision making with ELECTRE III method based on interval-valued intuitionistic fuzzy information," Applied Mathematical Modelling, vol. 40, no. 2, pp.1554-64, 2016

[35] G. H. Tzeng and J. J. Huang, "Multiple attribute decision making, methods and applications," Taylor \& Francis group, Boca Raton, 2011.

[36] H. Li and J. Wang, "An Improved Ranking Method for ELECTRE III," 2007 International Conference on Wireless Communications, Networking and Mobile Computing, 2007, pp. 6659-6662, doi: 10.1109/WICOM.2007.1634. 
[37] A. Evans, V. Strezov, T. J. Evans, "Assessment of sustainability indicators for renewable energy technologies," Renewable and Sustainable Energy Reviews, vol. 13, no. 5, pp. 1082-1088, 2009, doi: 10.1016/j.rser.2008.03.008.

[38] B. Vučijak, T. Kupusović, S. Midžić-Kurtagić and A. Ćerić, "Applicability of multicriteria decision aid to sustainable hydropower," Applied Energy, vol. 101, pp. 261-267, 2013, doi: 10.1016/j.apenergy.2012.05.024.

[39] K. Kaygusuz, "Sustainable development of hydroelectric power," Energy Sources, vol. 24, no. 9, pp. 803-815, 2002, doi: 10.1080/00908310290086725.

[40] A. M. Mayeda, A. D. Boyd, "Factors influencing public perceptions of hydropower projects: A systematic literature review," Renewable and Sustainable Energy Reviews, vol. 121, pp. 109713, 2020, doi: 10.1016/j.rser.2020.109713.

[41] K. J. Mohan and R. P. Kumar, "Earthquakes and dams in India: an overview," International Journal of Civil Engineering and Technology, vol. 4, no. 6, pp. 101-115, 2013.

[42] A. Maxim, "Sustainability assessment of electricity generation technologies using weighted multi-criteria decision analysis," Energy Policy, vol. 65, pp. 284-297, 2014, doi: /10.1016/j.enpol.2013.09.059.

[43] M. M. Cernea, Hydropower dams and social impacts: a sociological perspective, The World Bank, 1997.

[44] Central Electricity Authority (CEA), Executive Summary, Ministry of Power, New Delhi, India, 2019. 